\title{
Dentoalveolar Injuries, Bicycling Accidents and Helmet Use in Patients Referred to a Norwegian Trauma Centre: A 12-year Prospective Study
}

\begin{abstract}
Background/Aim:

Despite its many benefits, bicycling carries the risk of accidents. Although numerous studies have reported the effect of helmet use on traumatic brain injury, it remains unclear if, and to what extent, helmet use reduces the risk of facial injuries. This is particularly true in regard to injuries of the lower face. In addition, there is limited evidence of the effect of helmet use on dentoalveolar injuries. Thus, the aim of this study was to determine the frequency and distribution of dentoalveolar injuries in bicycling accidents and to explore the influence of helmet use.
\end{abstract}

Material and Methods:

A total of 1543 bicyclists were included from the trauma registry of a Norwegian tertiary trauma center over a 12-year period. Data was collected prospectively, including patient characteristics, type of injury, and helmet use. The prevalence of dentoalveolar injuries was assessed in conjunction with helmet use and facial fractures.

Results:

Twenty-five percent of the patients had maxillofacial injuries, and $18 \%$ of those with facial fractures exhibited concomitant dentoalveolar injuries. The most common type of dentoalveolar injury was tooth fractures (39\%). The most frequent location of facial fractures with combined dentoalveolar injuries was the maxilla, which had fractured in 32 patients. Women had a higher risk of sustaining dentoalveolar injuries compared to men (odds ratio $1.50,95 \%$ confidence interval $1.02-2.22)$. There were 1257 patients $(81 \%)$ who had reliable 
registration of helmet use; $54 \%$ of these wore a helmet, while $46 \%$ did not. Helmet users had an increased risk of dentoalveolar injuries compared to non-helmeted bicyclists (adjusted odds ratio $1.54,95 \%$ confidence interval $1.02-2.31$ ).

\section{Conclusions:}

Dentoalveolar injuries are fairly common in trauma patients admitted to a trauma center following bicycling accidents. Bicycling helmets are associated with an increased risk of dentoalveolar injuries.

\section{Keywords}

Tooth Injuries; Maxillofacial Injuries; Head Protective Devices; Wounds and Injuries; Epidemiology 


\section{Introduction}

Bicycling is a popular mode of transportation and form of exercise. About half of the population in the European Union (EU) use a bicycle, and the EU aims to increase bicycle use by $50 \%$ from $2019 / 2020$ to $2030 .{ }^{1}$ Cycling is associated with increased cardiorespiratory fitness, and there is an inverse relationship between cycling and all-cause mortality, cancer, being overweight, and obesity. ${ }^{2}$ In addition, cycling is beneficial in terms of pollution reduction and is more cost-efficient compared to the use of cars. ${ }^{1}$

Despite its many benefits, cycling carries the risk of accidents. Head and facial injuries are among the most common bicycle-related injuries, ${ }^{3}$ and bicycling accidents have been cited as the mechanism of injury in $1.1-18 \%$ of all facial fractures in several countries. ${ }^{4}$ Gassner and colleagues found that 565 of 6000 patients who presented with facial injury at their emergency department had bicycle-related facial injuries. In addition, they reported that $50.1 \%$ of all sports-related orofacial injuries had concomitant dental injuries. ${ }^{5}$

Treating dental injuries in patients with maxillofacial trauma can be time-consuming and financially demanding, and often requires more treatment than the facial fracture itself. ${ }^{6}$ In addition, injuries to the teeth can cause psychological, aesthetic, functional, and social impairment. ${ }^{7}$ Dental trauma may also have a negative effect on the quality of life. ${ }^{8}$

The EU aims to halve the rate of fatalities and serious injuries related to bicycling. ${ }^{1}$ Helmet wear is protective against head injuries as well as injury to the upper face and midface. However, there is controversy regarding helmet use and the possible increased risk of injury to the lower face. ${ }^{9-11}$ A recent meta-analysis by $\mathrm{H} \varnothing y \mathrm{e}^{12}$ found a $28 \%$ risk reduction in facial injury in helmeted riders. However, none of the studies included in that analysis examined the 
effect of helmet wear on dentoalveolar injuries..$^{3,9,11-29}$ To the authors' knowledge, only one previous study on the effect of helmet use on dental injury has been published, and that study reported that helmeted patients had a $10 \%$ reduction in dental injuries. ${ }^{30}$ The same study found that the protective effect of helmets on facial hard tissue diminishes from the upper to the lower part of the face, but there was no protective effect on the lower face soft tissues. ${ }^{30}$ Thus, it is unclear if, and to what extent, helmet use affects the risk of injury to the teeth and alveolar bones in bicycling accidents.

The aim of this study was to examine the incidence and type of dentoalveolar injury in trauma patients admitted with bicycling-related injuries. Further aim was to examine if helmet use affected the risk of dentoalveolar injuries.

\section{Materials and Methods}

Prospectively collected data from the Oslo University Hospital, Ullevål (OUH) trauma registry (TR-OUH) was obtained for the 12-year period from 2005 to 2016 . OUH is a Level I trauma center serving a population of approximately 3 million people. The trauma patients are either admitted directly or referred via smaller hospitals in the region. The Department of Maxillofacial Surgery has a 24-hour on-call service and is consulted for patients with maxillofacial trauma, including soft tissue injuries to the face and neck.

The TR-OUH includes all patients received by a trauma team, as well as patients with penetrating injuries proximal to the elbow or knee, patients with Abbreviated Injury Scale 1990 Revision Update 98 (AIS 98) ${ }^{31}$ Head severity code $\geq 3$, and patients with Injury Severity Score $(\text { ISS })^{32}>10$ admitted $<24$ hours after injury. ${ }^{33}$ 
Trauma registry data was obtained for all patients admitted with bicycling injuries. Variables included information on age, gender, and helmet use as well as the following AIS 98 codes for facial fractures; 2506* (fractures of the mandible), 2508* (fractures of the maxilla), 2510* (fractures of the nose), 2512* (fractures of the orbit), and 2518* (fractures of the zygoma). AIS codes included for dentoalveolar injuries were $2502 *$ (fractures of the alveolar ridge), 251499.1 (injury to teeth, not further specified), 251402.1 (dislocation or loosened), 251404.2 (fracture), and 251406.1 (avulsion). The AIS 98 code for fracture of the nose $\left(2510^{*}\right)$ also contains patients with epistaxis, but patients who experienced isolated epistaxis without skeletal injury of the nose were not included in the analyses.

The study was conducted on anonymized data. It was approved and considered exempt from patient consent requirements by the Data Protection Officer at OUH (17/18831).

Statistical analyses were performed using IBM SPSS version 25 for Windows (SPSS, Inc, Chicago, IL). Patient characteristics are presented as means with standard deviations (SD) or percentage. Independent sample Student's t-test was used to detect differences between groups for continuous variables. Chi-squared test was used to investigate differences between groups for categorical variables. Logistic regression analysis was performed to adjust for confounding effects of gender and age. The results are given as odd ratios (OR) with 95\% confidence intervals (CI). One-way ANOVA test was performed to compare age for patients with isolated dentoalveolar injuries, combined facial and dentoalveolar injuries, and facial fractures alone. A two-tailed $\mathrm{P}<0.05$ was considered statistically significant. 


\section{Results}

During the study period, 1570 trauma patients with bicycle-related accidents were admitted to the hospital. Of these, 27 pedestrians who had been struck by a cyclist were excluded from further analysis. Of the 1543 remaining patients (Table 1), 27\% were women and $73 \%$ were men. There were 383 cyclists $(25 \%)$ who had maxillofacial fractures, injuries to the teeth, and/or injuries to the alveolar process (Table 2). Isolated facial fractures were seen in 260 of the 383 patients $(68 \%)$, isolated dentoalveolar injuries in $53(14 \%)$, and combined facial and dentoalveolar injuries in 70 patients (18\%). The 123 patients with dentoalveolar injuries (8\% of the total material, $32 \%$ of cyclists with maxillofacial fractures) had a higher occurrence of facial fractures compared to patients without dentoalveolar injuries (OR 5.34, 95\% CI 3.65 7.80). The total number of dentoalveolar injuries among the 123 patients was 135 .

Women had higher odds of sustaining dentoalveolar injuries compared to men (OR 1.50, 95\% CI $1.02-2.22$ ). The mean age of the patients with dentoalveolar injuries was $40.7 \pm 17.2$ years (range 6-91 years). The age distribution of patients with and without dentoalveolar injuries is shown in Figure 1. Patients with isolated dentoalveolar injuries were younger than those with either combined facial and dentoalveolar injuries or isolated facial fractures $(36.5 \pm$ 17.8 years vs. $43.8 \pm 16.1$ years vs. $46.1 \pm 17.8$ years, $p=0.001)$.

Figure 2 shows the distribution of the 135 dentoalveolar injuries. Tooth fractures were the most frequent type $(n=53,39 \%)$, followed by avulsions $(n=30,22 \%)$, luxations $(n=26$, $19 \%)$, and alveolar process fractures $(n=20,15 \%)$. Four of the patients who sustained alveolar process fractures had isolated fractures while 16 patients had concomitant facial fractures $(\mathrm{n}=11)$ and/or other types of dentoalveolar injuries $(\mathrm{n}=11)$. 
The most frequent combinations of facial fracture and dentoalveolar injury were, in descending order: fractures of the maxilla, nose, and mandible. However, cyclists with fractures of the mandible had a higher risk of dentoalveolar injuries compared to the other facial fracture locations (OR 11.5, 95\% CI 6.79 - 19.6) (Table 3). Fractures of the nose and maxilla were also associated with dentoalveolar injury. There was no significant association between dentoalveolar injury and fracture of the orbit or zygoma.

There was no information on helmet use for $286(19 \%)$ of the cyclists who had been admitted. Consequently, these were excluded from analyses of the effects of helmet use on dentoalveolar injury. Of the remaining 1257 injured cyclists with known helmet status (Table 1), 54\% wore a helmet. Dentoalveolar injuries were more prevalent among helmeted cyclists compared to non-helmeted cyclists (unadjusted OR 1.52, 95\% CI 1.02 - 2.29; adjusted for gender and age OR 1.54, 95\% CI $1.02-2.31$ ). There were 109 of the 123 patients with dentoalveolar injuries who had known status of helmet use (Table 1), of whom 61 patients had 99 concomitant facial fractures (Table 4).

\section{Discussion}

The present study shows that dentoalveolar injury is common among trauma patients admitted following bicycling accidents, with a frequency of $8 \%$ in the study population. In addition, $18 \%$ of all patients with maxillofacial injury had both facial fractures and dentoalveolar injury. This is comparable to the findings by Boffano et al., ${ }^{4}$ who reported an incidence of $25 \%$, and Lindqvist et al. ${ }^{34}$ reporting that $16 \%$ of all cyclists with facial fractures had dental injuries. Injuries to the teeth and periodontium often require prompt attention and treatment as delay may lead to a worse outcome. ${ }^{35,36}$ The high proportion of combined facial fractures and 
dentoalveolar injuries in bicycling accidents highlights the need for surgeons with dental competence at trauma centers.

Although helmet use is not mandatory in Norway, the majority of the study population used helmets. Helmets are effective for preventing injuries to the head, midface, and upper face, but there is divergent evidence regarding their effect on lower face injuries. ${ }^{9-11}$ The present study found that helmet users had an increased risk of sustaining dental injuries. This is in accordance with the study by Linn et al., ${ }^{37}$ who reported a similar although not significant finding in their study of 1462 children involved in bicycling accidents. Like the present study, Benjamin et al. ${ }^{30}$ found that helmet users had an increased risk of dental injuries. The effect size in the present study was, however, larger with an OR of 1.54 compared to 1.10 in the study by Benjamin et al., ${ }^{30}$ This could partly be due to differences in the study population, namely that the bicyclists in the current study were admitted to a tertiary trauma center whereas the latter study used records from both trauma centers and emergency departments. Another possibility could be that the study populations varied in age distribution, although comparing this was not possible as the study by Benjamin et al. lacked in demographic data. ${ }^{30}$ The current study did not, however, find that age influenced the risk of dentoalveolar injury.

The reason for the increased risk of dentoalveolar injury with helmet use could be that the helmet inflicts a second impact to the lower face when it hits an object, and/or that the midface, which is otherwise protected when a helmet is worn, absorbs the energy of the trauma in the non-helmeted rider. ${ }^{10}$ The former is supported by a study which analyzed helmet damage in conjunction with head and facial injury in 105 cyclists. That study found that $69.6 \%$ of the patients with injuries below the Frankfort plane had impact to the front rim of the helmet. ${ }^{38}$ Intuitively, bicycling helmets with a chin guard would provide protection to 
these areas of the face. Although they exist on the market, the authors' impression is that they are seldom used. The reason for this could be that they are not readily available in stores or that they are viewed as being impractical or unfashionable. Thus, efforts should be made to increase awareness of the effectiveness of these helmets in the cycling part of the population.

Behavior adaption in the cyclists who wore helmets could also have influenced the risk of dentoalveolar injuries if the use of helmets led to increased risk-taking and consequently more accidents. ${ }^{39-41}$ Supporting this, a study of 1504 Norwegian cyclists found that helmet use was more common in a sub-population of cyclists who cycled more aggressively and used helmets as part of their cycling identity. ${ }^{42}$ In contrast to this, however, there is evidence that helmeted cyclists ride more carefully, more often obey traffic laws and use lights at night compared to non-helmeted cyclists. ${ }^{43,44}$ Another possible explanation for the increased risk of dentoalveolar injuries in helmet users could be that helmets are used more often in high-risk cycling, such as mountain biking, and these were over-represented in the study population. The study did not, however, examine the crash details.

Patients with maxillary fractures most commonly had dentoalveolar injuries. However, the association of fracture location and dentoalveolar injury was strongest in cyclists with mandible fractures compared to the other facial fracture locations, with an OR of 11.5. The latter is in accordance with the study by Lieger and co-workers, ${ }^{45}$ who found that patients with mandible fractures were more likely to have concomitant dental injuries than patients with other facial bone fractures. The reason could be that a blow to the mandible causes its teeth to strike the teeth of the maxilla, resulting in dental injury in the latter due to its weaker bone support. ${ }^{45}$ Similar to the findings in the present study, Lieger and colleagues also found that tooth fractures were the most common dental injury, followed by avulsions. ${ }^{45}$ 
The current study has some weaknesses. The TR-OUH does not record whether trauma patients are edentulous. In addition to possibly under-estimating the risk of dentoalveolar injury, the inclusion of edentulous patients could have biased the analysis if they were more or less likely to use a helmet. Edentulous people in Norway, however, constitute $<2 \%$ of the population, which makes it unlikely that this could have affected the results significantly. ${ }^{46}$ Furthermore, the age distribution in the present study is different from that of the edentulous part of the population. ${ }^{46}$

Another possible shortcoming is that the majority of the trauma patients were most likely not checked by an examining surgeon with dental competence in the emergency department. In OUH, trauma patients with dentoalveolar injuries are most often examined by a maxillofacial surgeon after they have been transferred to the high-dependency unit or intensive care unit for observation if their facial injury does not necessitate prompt examination. A thorough tertiary survey is always done before discharge from the critical care/high dependency unit, but still it is possible that dentoalveolar injuries could have been overlooked in some patients whose only facial injuries were uncomplicated injuries of the teeth. This could have led to an underestimation of the incidence of dentoalveolar injuries.

Lastly, only patients with either suspected or confirmed serious injuries were included. Thus, patients with minor to moderate injuries who were fully protected by wearing (or not wearing) a helmet were not included. This could have influenced the analysis of the effect of helmet use on dentoalveolar injury. 
In conclusion, the present study shows that dentoalveolar injury is fairly common in bicycling accidents. Helmet users had increased risk of dentoalveolar injury, adding evidence to the hypothesis that helmet use presents a higher likelihood of sustaining injury to the lower face. Efforts should therefore be made to increase the use of alternative helmets that protect this area.

\section{Conflict of Interest}

The authors have no conflicts of interest to declare.

\section{References}

1. European Cyclists' Federation (ECF) asbl. EU Cycling Strategy - Recommendations for Delivering Green Growth and an Effective Mobility System in 20302017 [Available from: https://ecf.com/sites/ecf.com/files/EUCS_full_doc_small_file.pdf.

2. Oja P, Titze S, Bauman A, de Geus B, Krenn P, Reger-Nash B, et al. Health benefits of cycling: a systematic review. Scand J Med Sci Sports. 2011;21:496-509.

3. Zibung E, Riddez L, Nordenvall C. Helmet use in bicycle trauma patients: a population-based study. Eur J Trauma Emerg Surg. 2015;41:517-21.

4. Boffano P, Roccia F, Gallesio C, Karagozoglu KH, Forouzanfar T. Bicycle-related maxillofacial injuries: a double-center study. Oral Surg Oral Med Oral Pathol Oral Radiol. 2013;116:275-80.

5. Gassner R, Bösch R, Tuli T, Emshoff R. Prevalence of dental trauma in 6000 patients with facial injuries: Implications for prevention. Oral Surg Oral Med Oral Pathol Oral Radiol Endod. 1999;87:27-33.

6. Oikarinen KS. Clinical management of injuries to the maxilla, mandible, and alveolus. Dent Clin North Am. 1995;39:113-31. 
7. Ramos-Jorge ML, Bosco VL, Peres MA, Nunes ACGP. The impact of treatment of dental trauma on the quality of life of adolescents - a case-control study in southern Brazil. Dent Traumatol. 2007;23:114-9.

8. Lee JY, Divaris K. Hidden consequences of dental trauma: The social and psychological effects. Pediatr Dent. 2009;31:96-101.

9. Stier R, Otte D, Muller C, Petri M, Gaulke R, Krettek C, et al. Effectiveness of Bicycle Safety Helmets in Preventing Facial Injuries in Road Accidents. Arch Trauma Res. 2016;5:e30011.

10. Hwang K, Jeon YM, Ko YS, Kim YS. Relationship between locations of facial injury and the use of bicycle helmets: A systematic review. Arch Plast Surg. 2015;42:407-10.

11. Joseph B, Azim A, Haider AA, Kulvatunyou N, O'Keeffe T, Hassan A, et al. Bicycle helmets work when it matters the most. Am J Surg. 2017;213:413-7.

12. Høye A. Bicycle helmets - To wear or not to wear? A meta-analyses of the effects of bicycle helmets on injuries. Accid Anal Prev. 2018;117:85-97.

13. Thompson DC, Thompson RS, Rivara FP, Wolf ME. A case-control study of the effectiveness of bicycle safety helmets in preventing facial injury. Am J Public Health. 1990;80:1471-4.

14. McDermott FT, Lane JC, Brazenor GA, Debney EA. The effectiveness of bicyclist helmets: a study of 1710 casualties. J Trauma. 1993;34:834-44.

15. Thomas S, Acton C, Nixon J, Battistutta D, Pitt WR, Clark R. Effectiveness of bicycle helmets in preventing head injury in children: case-control study. BMJ. 1994;308:173-6.

16. Thompson DC, Nunn ME, Thompson RS, Rivara FP. Effectiveness of bicycle safety helmets in preventing serious facial injury. JAMA. 1996;276:1974-5.

17. Hansen KS, Engesaeter LB, Viste A. Protective effect of different types of bicycle helmets. Traffic Inj Prev. 2003;4:285-90. 
18. Heng KW, Lee AH, Zhu S, Tham KY, Seow E. Helmet use and bicycle-related trauma in patients presenting to an acute hospital in Singapore. Singapore Med J. 2006;47:367-72.

19. Sze N, Tsui K, Wong S, So F. Bicycle-related crashes in Hong Kong: Is it possible to reduce mortality and severe injury in the metropolitan area? Hong Kong $\mathrm{J}$ Emerg Me. 2011;18:136-43.

20. Amoros E, Chiron M, Martin JL, Thelot B, Laumon B. Bicycle helmet wearing and the risk of head, face, and neck injury: a French case-control study based on a road trauma registry. Inj Prev. 2012;18:27-32.

21. Bergenstal J, Davis SM, Sikora R, Paulson D, Whiteman C. Pediatric bicycle injury prevention and the effect of helmet use: the West Virginia experience. W V Med J. 2012;108:78-81.

22. Wagner JMD, Rai ABS, Ituarte FBS, Tillou AMD, Cryer HMDPHD, Hiatt JRMD. Two-wheel vehicular trauma: An age-based analysis. Am Surgeon. 2012;78:1066-70.

23. Rizzi M, Stigson, H, Krafft, M. Cyclist injuries leading to permanent medical impairment in Sweden and the effect of bicycle helmets. 2013 [Available from: http://www.ircobi.org/wordpress/downloads/irc13/pdf_files/46.pdf.

24. Webman R, Dultz LA, Simon RJ, Todd SR, Slaughter D, Jacko S, et al. Helmet use is associated with safer bicycling behaviors and reduced hospital resource use following injury. J Trauma Acute Care. 2013;75:877-81.

25. Otte D, Wiese B. Influences on the risk of injury of bicyclists' heads and benefits of bicycle helmets in terms of injury avoidance and reduction of injury severity. SAE Int J Trans Safety. 2014;2:257-67.

26. Dinh MM, Kastelein C, Hopkins R, Royle TJ, Bein KJ, Chalkley DR, et al. Mechanisms, injuries and helmet use in cyclists presenting to an inner city emergency department. Emerg Med Australas. 2015;27:323-7. 
27. Kaushik R, Krisch IM, Schroeder DR, Flick R, Nemergut ME. Pediatric bicyclerelated head injuries: a population-based study in a county without a helmet law. Inj Epidemiol. 2015;2:16-25.

28. Olofsson E, Bunketorp O, Andersson A-L. Helmet use and injuries in children's bicycle crashes in the Gothenburg region. Safety Sci. 2017;92:311-7.

29. Sethi M, Heidenberg J, Wall SP, Ayoung-Chee P, Slaughter D, Levine DA, et al. Bicycle helmets are highly protective against traumatic brain injury within a dense urban setting. Injury. 2015;46:2483-90.

30. Benjamin T, Hills NK, Knott PD, Murr AH, Seth R. Association between conventional bicycle helmet use and facial injuries after bicycle crashes. JAMA Otolaryngol Head Neck Surg. 2019;145:140-5.

31. Association for the Advancement of Automotive Medicine. The Abbreviated Injury Scale 1990 Revision Update 98. Des Plains, IL 60018. USA: Association for the Advancement of Automotive Medicine.

32. Baker SP, O'Neill B, Haddon W, Jr., Long WB. The injury severity score: a method for describing patients with multiple injuries and evaluating emergency care. J Trauma. 1974;14:187-96.

33. Søvik S, Skaga NO, Hanoa R, Eken T. Sudden survival improvement in critical neurotrauma: An exploratory analysis using a stratified statistical process control technique. Injury. 2014;45:1722-30.

34. Lindqvist C, Sorsa S, Hyrkäs T, Santavirta S. Maxillofacial fractures sustained in bicycle accidents. Int J Oral Maxillofac Surg. 1986;15:12-8.

35. Bringhurst C, Herr RD, Aldous JA. Oral trauma in the emergency department. Am J Emerg Med. 1993;11:486-90. 
36. Andreasen JO, Andreasen FM, Skeie A, Hjørting-Hansen E, Schwartz O. Effect of treatment delay upon pulp and periodontal healing of traumatic dental injuries - a review article. Dent Traumatol. 2002;18:116-28.

37. Linn S, Smith D, Sheps S. Epidemiology of bicycle injury, head injury, and helmet use among children in British Columbia: a five year descriptive study. Canadian Hospitals Injury, Reporting and Prevention Program (CHIRPP). Inj Prev. 1998;4:122-5.

38. Ching RP, Thompson DC, Thompson RS, Thomas DJ, Chilcott WC, Rivara FP. Damage to bicycle helmets involved with crashes. Accid Anal Prev. 1997;29:555-62.

39. Robinson DL. Bicycle helmet legislation: Can we reach a consensus? Accid Anal Prev. 2007;39:86-93.

40. Fyhri A, Phillips RO. Emotional reactions to cycle helmet use. Accid Anal Prev. 2013;50:59-63.

41. Phillips RO, Fyhri A, Sagberg F. Risk compensation and bicycle helmets. Risk Anal. 2011;31:1187-95.

42. Fyhri A, Bjørnskau T, Backer-Grøndahl A. Bicycle helmets - A case of risk compensation? Transp Res Part F Traffic Psychol Behav. 2012;15:612-24.

43. McGuire L, Smith N. Cycling safety: injury prevention in Oxford cyclists. Inj Prev. 2000;6:285-7.

44. Farris C, Spaite DW, Criss EA, Valenzuela TD, Meislin HW. Observational evaluation of compliance with traffic regulations among helmeted and nonhelmeted bicyclists. Ann Emerg Med. 1997;29:625-9.

45. Lieger O, Zix J, Kruse A, Iizuka T. Dental injuries in association with facial fractures. J Oral Maxillofac Surg. 2009;67:1680-4.

46. Holst D, Skau I. Natural teeth and dental status in Norway. How large is the social inequality? Nor Tannlegeforen Tid. 2010;120:164—9. 
Table 1. Comparison of patients with and without dentoalveolar injuries with respect to age, gender and helmet use.

\begin{tabular}{lcccc}
\hline & $\begin{array}{c}\text { Total } \\
(\mathrm{n}=1543)\end{array}$ & $\begin{array}{c}\text { Dentoalveolar injury } \\
(\mathrm{n}=123)\end{array}$ & $\begin{array}{c}\text { No dentoalveolar } \\
\text { injury }(\mathrm{n}=1420)\end{array}$ & P value \\
\hline $\begin{array}{l}\text { Age (years), mean (SD) } \\
\text { Gender }\end{array}$ & $39.2(18.9)$ & $40.7(17.2)$ & $39.1(18.9)$ & $0.343^{\S}$ \\
$\quad$ Male, $\mathrm{n}(\%)$ & $1126(73)$ & $80(65)$ & $1046(74)$ & $0.039^{\ddagger}$ \\
$\quad$ Female, $\mathrm{n}(\%)$ & $417(27)$ & $43(35)$ & $374(26)$ & \\
Helmet use & $678(54)$ & $69(63)$ & $609(53)$ & \\
$\quad$ Helmet, $\mathrm{n}(\%)^{\dagger}$ & $578(46)$ & $40(37)$ & $538(47)$ & $0.041^{\ddagger \ddagger}$ \\
$\quad$ No helmet, $\mathrm{n}(\%)^{\dagger}$ & 286 & 14 & 273 & \\
$\quad \begin{array}{l}\text { Unknown helmet } \\
\text { status }\end{array}$ & & & & \\
\hline
\end{tabular}

$\mathrm{n}$; number of patients. SD; Standard deviation. $\mathrm{Cl}$; confidence interval. * Cyclists with unknown status for helmet use were not included in the analysis. + Percent of population with known status for helmet use.

${ }^{\S}$ Independent sample Student's t-test. ${ }^{\ddagger}$ Chi-squared test.

Table 2. Distribution of injury types and combinations of maxillofacial injuries from the study population of 1543 cyclists.

\begin{tabular}{lc}
\hline Type of injury & $\mathrm{n}$ \\
\hline Isolated dentoalveolar injuries & 53 \\
Combined facial and dentoalveolar injuries & 70 \\
Isolated facial fractures & 260 \\
Total number of maxillofacial injuries & 383 \\
\hline
\end{tabular}

$\mathrm{n}$; number of patients. 
Table 3. Distribution of 632 facial fractures and 121 concomitant dentoalveolar injuries in the 1543 patients.

\begin{tabular}{llcc}
\hline Fracture type & \multicolumn{1}{c}{$\mathrm{n}(\%)$} & $\begin{array}{c}\text { Concomitant DA } \\
\text { injury }(\%)\end{array}$ & OR (95\% CI) \\
\hline Maxilla & $182(11.8)$ & $39(2.5)$ & $3.96(2.60-6.03)$ \\
Nose & $109(7.1)$ & $29(1.9)$ & $6.13(3.86-9.75)$ \\
Mandible & $66(4.3)$ & $27(1.7)$ & $11.5(6.79-19.6)$ \\
Orbit & $144(9.3)$ & $15(1.0)$ & $1.39(0.79-2.46)$ \\
Zygoma & $131(8.5)$ & $11(0.7)$ & $1.06(0.56-2.03)$ \\
\hline
\end{tabular}

n; number of fractures. DA; Dentoalveolar. OR; Odds ratio. CI; Confidence interval.

Table 4. Distribution of the 99 concomitant facial fractures in 61 of the 109 patients with dentoalveolar injury and known status for helmet use.

\begin{tabular}{lcccc}
\hline $\begin{array}{l}\text { Fractures } \\
(\mathrm{n}=99)\end{array}$ & $\begin{array}{c}\text { Age (years) } \\
\text { mean (SD) }\end{array}$ & $\begin{array}{c}\text { Helmeted } \\
\text { patients }\end{array}$ & $\begin{array}{c}\text { Non-helmeted } \\
\text { patients }\end{array}$ & $\begin{array}{c}\text { Proportion of } \\
\text { patients (\%) } \\
(95 \% \mathrm{CI})\end{array}$ \\
\hline Maxilla $(\mathrm{n}=32)$ & $46.6(16.6)$ & 13 & 19 & $29.4(21.6-38.5)$ \\
Nose $(\mathrm{n}=26)$ & $45.8(16.5)$ & 14 & 12 & $23.9(16.8-32.7)$ \\
Mandible $(\mathrm{n}=24)$ & $43.6(17.2)$ & 17 & 7 & $22.0(13.7-28.7)$ \\
Orbit $(\mathrm{n}=10)$ & $46.6(16.4)$ & 3 & 7 & $9.2(5.1-16.1)$ \\
Zygoma $(\mathrm{n}=7)$ & $48.7(16.8)$ & 1 & 6 & $6.4(3.1-12.7)$ \\
\hline
\end{tabular}

n; number of fractures. SD; Standard deviation. CI; confidence interval. 


\section{Figure legends}

\section{Figure 1.}

Age distribution in 5-year intervals for the 1420 patients without and the 123 patients with dentoalveolar injuries.

\section{Figure 2.}

Distribution of the 135 dentoalveolar injuries in the 123 patients with dentoalveolar injuries from the study population of 1543 cyclists. 